\title{
LOW ENERGY PROTON CAPTURE RESONANCES IN THE CHLORINE ISOTOPES
}

\author{
by J. KUPERUS \\ Fysisch Laboratorium der Rijksuniversiteit te Utrecht
}

\section{Synopsis}

A search was made for proton capture resonances in the chlorine isotopes, making use of natural and enriched targets. Eighteen resonances have been observed in the proton energy region from 300 to $900 \mathrm{keV}$, and their isotopic assignment has been established from a comparison of the yield curves.

Single gamma-ray spectra have been recorded at all resonances. The characteristic lines observed in the spectra confirmed the isotopic assignment, made from the yield curves. Gamma-ray yields are given in absolute measure. Branching ratios have been measured for transitions to known ${ }^{36} \mathrm{~A}$ and ${ }^{38 \mathrm{~A}}$ levels.

1. Introduction. The existence of 86 resonances for the reactions ${ }^{35,37} \mathrm{Cl}(p, \gamma)^{36,38} \mathrm{~A}$ in the region from 500 to $2150 \mathrm{keV}$ proton energy has been mentioned by Broström, Madsen and Madsen ${ }^{1}$ ). Tangen ${ }^{2}$ ) reported four resonances at proton energies of 427, 447, 500 and $532 \mathrm{keV}$ in the region from 400 to $550 \mathrm{keV}$.

In the present investigation a search was made for resonances in the $300-900 \mathrm{keV}$ region. Eighteen resonances have been found and their isotopic assignment has been established. For these resonances single gamma-ray spectra were recorded from which relative line intensities for the most important transitions were deduced.

2. Experimental. Protons were accelerated with the $900 \mathrm{kV}$ Utrecht cascade generator and analysed with a $90^{\circ}$ deflection magnet with an energy resolution of $0.25 \%{ }^{3}$ ).

The proton energy was determined by measuring the magnetic field with a proton resonance magnetic flux meter ${ }^{4}$ ).

Targets containing chlorine of natural abundance and also enriched targets were used. The natural chlorine targets consisted of a layer of $\mathrm{CaCl}_{2}$ or $\mathrm{CoCl}_{2}$ evaporated onto a $\frac{1}{2} \mathrm{~mm}$ copper backing. Enriched targets containing chlorine gas shot into a copper backing were kindly supplied by the „Laboratorium voor Massaspectrometrie" in Amsterdam. Enriched targets 
consisting of a layer of $\mathrm{AgCl}$ on a nickel backing were obtained from the "Atomic Energy Research Establishment" in Harwell.

The gamma radiation was detected with a $4^{\prime \prime} \times 4^{\prime \prime} \mathrm{Nal}$ crystal at an angle of $55^{\circ}$ to the proton beam. The energy resolution of the crystal amounted to $6.6 \%$ for a gamma line of $1.78 \mathrm{MeV}$.

Spectra were recorded with a 256 channel R.C.L. pulse-height analyser.

3. Results. $\Lambda$ yield curve with a target of natural abundance in the region from $400-900 \mathrm{keV}$ and enriched target yield curves for those parts of this energy region where chlorine resonances were established is shown in figure 1. No chlorine resonances have been observed in the region from $300-400 \mathrm{keV}$.

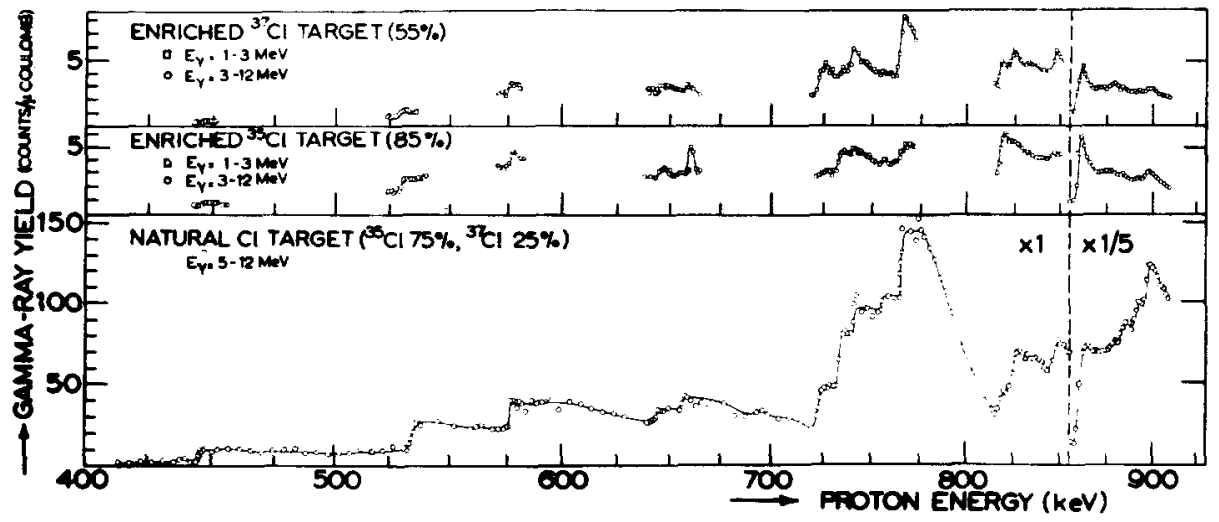

Fig. 1. Gamma-ray yield curves with a target of natural abundance for the energy region from $400-900 \mathrm{keV}$ and with targets enriched in ${ }^{37} \mathrm{Cl}$ and $35 \mathrm{Cl}$ respectively for those parts of this energy region where chlorine resonances are observed.

Comparison of the yield curves provides a unique isotopic assignment. The targets had not been analysed mass-spectroscopically, but the enrichments indicated in fig. 1 were computed from the observed gamma-ray yield ratios. Resonances were established at the following proton energies: ${ }^{35} \mathrm{Cl}: \quad 445.9,533.8,575.9,644.2,656.8,734.6,755.4,818.2,861.4,885.7$, $893.0,899.2 \mathrm{keV}$;

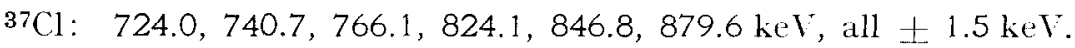

Only two of the resonances mentioned by Tangen ${ }^{2}$ ) have been observed in the present investigation. The two other resonances may have been too weak, but the one mentioned to be at $427 \mathrm{keV}$ proton energy may also have been due to ${ }^{15} \mathrm{~N}$ contamination on the target.

For each of the established resonances a gamma-ray spectrum was recorded.

The first level in ${ }^{36} \mathrm{~A}$ is known at an energy of $\left.1.98 \mathrm{MeV} 5\right)^{6}$ ) and the first levels in $38 \mathrm{~A}$ are known at energies of 2.15 and $3.75 \mathrm{MeV} 7$ ). For all 
resonances assigned to the ${ }^{35} \mathrm{Cl}(p, \gamma)^{36} \mathrm{~A}$ reaction a transition of $1.95 \pm 0.02$ $\mathrm{MeV}$ was observed and for the resonances assigned to the reaction ${ }^{37} \mathrm{Cl}(p, \gamma){ }^{38} \mathrm{~A}$ gamma lines of $1.63 \pm 0.02$ and $2.18 \pm 0.02 \mathrm{MeV}$ were observed, which strongly supports the isotopic assignment, made from the yield curves.

For each resonance the observed energies for transitions to and from known levels and their intensities relative to the transition from the first excited level to the ground state are shown in table I. For most of the resonances other gamma lines have been observed. To determine the complete decay scheme for each resonance, however, coincidence and sum-coincidence measurements are in progress.

TABLE I

\begin{tabular}{|c|c|c|c|c|c|c|c|}
\hline \multicolumn{8}{|c|}{$\begin{array}{l}\text { The proton energies, gamma-ray energies and their relative intensities for transitions to and } \\
\text { from known levels and an estimate for the resonance strength of all observed chlorine re- } \\
\text { sonances. The transitions are indicated with their initial and final levels, }(0)=\text { ground state } \\
\text { (1) = first excited state etc., }(r)=\text { resonance level. The error in the gallnla-ray energies } \\
\text { amounts to } 2 \% \text {, and in the relative intensities up to about } 10 \% \text {. }\end{array}$} \\
\hline \multicolumn{8}{|c|}{${ }^{35} \mathrm{Cl}(p, \gamma)^{36} \mathrm{~A}$} \\
\hline \multirow{2}{*}{$\begin{array}{c}E_{p} \\
(\mathrm{keV})\end{array}$} & \multirow{2}{*}{$\begin{array}{c}E_{x}\left({ }^{36} \mathrm{~A}\right) \\
(\mathrm{MeV})\end{array}$} & \multicolumn{5}{|c|}{$E_{\gamma}(\mathrm{MeV})$ and Relative Intensity } & \multirow{2}{*}{$\begin{array}{c}\text { Resonance } \\
\text { Strength } \\
(2 J+1) \Gamma_{p} \Gamma_{\gamma} I \\
(\mathrm{meV})\end{array}$} \\
\hline & & $(r) \rightarrow(0)$ & $(r) \rightarrow(0)$ & $\begin{aligned}(1) & \rightarrow(0) \\
\text { int } & =100\end{aligned}$ & & & \\
\hline 445.9 & 8.94 & \multirow{12}{*}{$9.23(31)$} & \multirow{3}{*}{$\begin{array}{l}7.09(55) \\
7.08(85)\end{array}$} & 1.95 & & & 3 \\
\hline 533.8 & 9.04 & & & 1.95 & & & 8 \\
\hline 575.9 & 9.07 & & & 1.94 & & & 7 \\
\hline 644.2 & 9.13 & & $7.15(47)$ & 1.96 & & & 4 \\
\hline 656.8 & 9.15 & & $7.15(52)$ & 1.95 & & & 3 \\
\hline 734.6 & 9.23 & & $7.22(97)$ & 1.95 & & & 20 \\
\hline 755.4 & 9.25 & & $7.35(82)$ & 1.96 & & & 4 \\
\hline 818.2 & 9.30 & & $7.3(3)$ & 1.95 & & & 3 \\
\hline 861.4 & 9.34 & & $7.40(51)$ & 1.95 & & & 100 \\
\hline 885.7 & 9.37 & & $7.50(100)$ & 1.97 & & & 20 \\
\hline 893.0 & 9.37 & & $7.35(64)$ & 1.95 & & & 40 \\
\hline 899.2 & 9.38 & & $7.47(50)$ & \multicolumn{2}{|l|}{1.97} & & - \\
\hline \multicolumn{8}{|c|}{${ }^{37} \mathrm{Cl}(p, \gamma)^{38} \mathrm{~A}$} \\
\hline & $F$ & & $E_{\gamma}(\mathrm{MeV})$ & nd Relative & Intensity & & $\begin{array}{c}\text { Resonance } \\
\text { Strength }\end{array}$ \\
\hline$(\mathrm{keV})$ & $(\mathrm{MeV})$ & $(y) \rightarrow(0)$ & $(r) \rightarrow(1)$ & $(v) \rightarrow(2)$ & $(2) \rightarrow(1)$ & $\begin{aligned} &(1) \rightarrow(0) \\
& \text { int. }=100\end{aligned}$ & $\underset{(\mathrm{meV})}{(2 J+1) \Gamma_{p} \Gamma_{\gamma^{\prime}} \Gamma}$ \\
\hline 724.0 & 10.91 & & $8.78(40)$ & $7.10(18)$ & $1.65(31)$ & 2.18 & 40 \\
\hline 740.7 & 10.96 & & & & $1.62(32)$ & 2.15 & 25 \\
\hline 766.1 & 10.98 & & $8.88(85)$ & $7.20(21)$ & $1.63(18)$ & 2.15 & 65 \\
\hline 824.1 & 11.0 .3 & $11.05(.37)$ & $8.95(39)$ & $7.30(15)$ & $1.62(35)$ & 2.13 & 40 \\
\hline 846.8 & 11.06 & & $8.90(50)$ & $7.35(36)$ & $1.64(20)$ & 2.12 & 20 \\
\hline 879.6 & 11.19 & & $8.95(27)$ & & $1.60(47)$ & 2.10 & 40 \\
\hline
\end{tabular}

The $Q$-values used for the calculation of the resonance excitation energies $\left(E_{x}\right)$ were $8.506 \mathrm{MeV}$ and $10.234 \mathrm{MeV}$ for the reactions ${ }^{35} \mathrm{Cl}(p, \gamma)^{36} \mathrm{~A}$ and ${ }^{37} \mathrm{Cl}(p, \gamma){ }^{38} \mathrm{~A}$, respectively $\left.{ }^{8}\right)$. The last column of the table gives an estimate 
for the resonance strength. As for most of the resonances the decay scheme is still partly unknown, these values contain an uncertainty of at least a factor 2. The resonance strength was calculated for the resonance at $533.8 \mathrm{keV}$, which decays mainly to the first excited state, by measuring the thick target yield. The yields for the other resonances were then compared with the yield for this resonance. For the resonance at $899.2 \mathrm{keV}$ the strength is not given, as part of its yield is due to the reaction $\mathrm{N}^{15}(p, \alpha \gamma) \mathrm{C}^{12}$ which has a strong resonance at this energy $\left.{ }^{9}\right)$.

Acknowledgements. This investigation was partly supported by the joint research program of the ,Stichting voor Fundamentecl Onderzoek der Materie" and the "Nederlandse Organisatie voor Zuiver Wetenschappelijk Onderzoek".

The author wishes to thank P. W. M. Glaudemans and F. C. Erné for their help during the measurements. He is greatly indebted to Professor P. M. Endt for his active help and his suggestions in the preparation of this paper.

Rereived 4-11-60.

REIERTENCLS

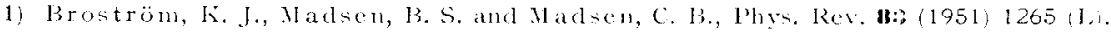

2) Tanget, R., let Kgl. Norslie Videnskabers Selskabs Skrifter (1946).

3) Smith, P. 13., and Braams, C. M., Nuclear lnstr. 8 (1960) 27.

4) Kuperus, J., Smulders, P. J. M. and Endt, P. M. Physica 2.7 (1959) 600.

5) 'Towle, J. H., Berenbaum, R. and Matthews, J. H., Proc. phys. Sur. I 70 (1957) 84.

6) Sperduto, A. and Burehner, W. W., Phy. Rev. 109) (1958) 462.

7) Kran\%, A. Z., and Watson, W. W., Plys. Rev. !l (1953) 1472.

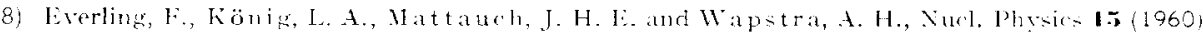
342 and $18(1960) 529$.

9) Schardt, A., Fowler, W. A. and I. auritsen, C. C. Phys. Ror. Ba (1952) 527. 